\title{
Travel times, operating and total costs: comparison between Tuscan trucked air cargo and an environmentally sustainable intermodal freight system
}

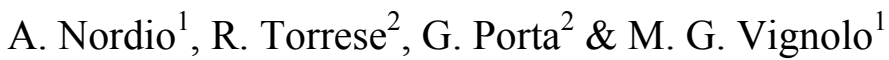 \\ ${ }^{I}$ Department of Machines, Energetic Systems and Transport, \\ Transportation Section, Genoa University, Italy \\ ${ }^{2}$ i.log. S.r.l., Genoa, Italy
}

\begin{abstract}
With the help of a case study, the present research tries to show that a certain new freight intermodal system can be a good solution only if it is accepted by transport operators. Therefore the system has to be sustainable from the point of view of time and cost. The first step of the research intends to identify the Tuscan Industrial Zones (Italy) characterized by an important air cargo export, to define the destination airports, to give a graphic description about ways that they are linked and to determinate current travel times and operating costs. It also introduces a project suggestion concerning a new intermodal system called "Metrocargo" which realizes a rapid road-railway modal exchange, evaluating travel times and operating costs relating to the regional railway lines that link the demand origin and the destination points.

The second step intends to quantify the time monetary value both in the event of trucked air cargo and in the event of rail transport, so as to define the total costs.

Keywords: trucked air cargo, rail transport, freight transport, travel time value, operating costs, total costs, intermodal system, trade-off coefficient.
\end{abstract}

\section{The Tuscan trucked air cargo export: industrial zones and air export, handler agents and destination airports}

In accordance with the Italian law no. 317/1991, the Tuscan local authority has recently defined an industrial zones map of the region. Twelve industrial 
manufacturing areas have been identified: Carrara, Capannori, Valdinievole, Prato, Santa Croce, Valdarno Superiore, Empoli, Castelfiorentino, Poggibonsi, Sinalunga, Arezzo and Casentino-Val Tiberina [1]. The export typologies are different, but only seven industrial zones produce goods transportable by air: Prato, Empoli and Casentino-Val Tiberina, which manufacture textiles and clothes, and Santa Croce, Valdarno Superiore, Castelfiorentino, Valdinievole, which manufacture dressed hide, leather and footwear. To complete the reference framework, production present outside the industrial zones has to be mentioned: goods include mechanical spare parts, valuable marbles, pharmaceutical drugs, vintage wines and toxic goods.

In order to find the trucked air cargo destination airports, the main handler agents working in this region (ALHA, Freschi\&Schiavoni, Swissport, Transcargo and Evergrin) have been interviewed. About one third of the air cargo exportation takes off from domestic airports (Milano-Malpensa, RomaFiumicino, Pisa, Bologna e Venezia) and the other two thirds take off from European hubs, such as Frankfurt, München, Amsterdam, Paris and Zürich.

The transportation planning process for extra-urban areas is based on a partition of the area in traffic zones. In this research it has been mainly necessary to consider the industrial zones' size. For this purpose, an infrastructural analysis concerning transport lines has been done. Distriparks, hubs, freight villages, logistic cities, transit points, transhipment harbours and cargo airports have been reported (Dalla Chiara et al [2]). So it has been possible to locate the demand origin points ("O" centroids) that either lie over important logistic centres or coincide with the infrastructural barycentres of the industrial zones, and the destination centroids too ("D" centroids) (Cascetta [3]). In particular 11 origin centroids have been fixed. Therefore 6 " $D$ " centroids coinciding with the airports which better represent the short and middle distance have been fixed and numbered (see the graphic network chart in figure 2).

\section{Estimate of trucked air cargo travel time and operating costs}

The trucked air cargo travel time estimate is related to a five-axled articulated vehicle as it appears more used than the other ones. The travel time is due to the sum of two components: the driving and the break time.

- The driving time reckoning methodology changes in accordance with the road type; for example, see below the extraurban roads and highways formulas (Cantarella and Festa [4]).

1) In the first case the driving time $T_{i}[h]$ related to the $i$-arc is given by the following formula:

where

$$
\mathrm{T}_{\mathrm{i}}=\mathrm{L}_{\mathrm{i}} / \mathrm{V}
$$

$L_{i}[\mathrm{~km}]$ is the generic i-arc length;

$$
V=V_{\max }-2 / 45 B-15 / 45 p
$$


$V_{\max }$ represents the presumed maximum speed, which varies according to the vehicles mass $\left(V_{\max }=70 \mathrm{~km} / \mathrm{h}\right.$ for lightweight vehicles, $V_{\max }=60 \mathrm{~km} / \mathrm{h}$ for average vehicles, $\mathrm{V}_{\max }=50 \mathrm{~km} / \mathrm{h}$ for heavy vehicles);

$B=1-t$ is the tortuosity index;

$t[\%]$ is the overtaking visibility; $\mathrm{p}[\% \mathrm{o}]=(\Sigma|\mathrm{h}|) / \mathrm{L}$ is the gradient that can be estimated thanks to CNR bulletin [5].

Therefore,

$$
T_{i}=\frac{L_{i}}{50-2 / 45(1-t)-15 / 45 p}
$$

The numerator of $p$ represents the difference in height summation, $L$ is the arc length; as this expression is hard to apply, the following formula would be better:

$$
p=0,02(\text { pia/100) }+0,06(\text { ond } / 100)+0,09(\mathrm{mon} / 100)
$$

where, pia is the arc length percentage related to a gradient $<3-4 \%$, ond is the arc length percentage related to a gradient $>4 \%$ and $<5-7 \%$, mon is the arc length percentage related to a gradient $>9 \%$.

In the graphic network chart (figure 2), it is possible to see the results.

2) In the second case the driving time $T_{i}[\mathrm{~h}]$ related to the $\mathrm{i}$-arc is given by the following CNR formula:

$$
T_{i}[h]=\max \left(T_{a}, T_{b}\right) \cdot L_{i} / 3600
$$

where

$T_{a}[\mathrm{~s} / \mathrm{km}]=3600 / 113-[1-\delta(p-0,025) \cdot 4,2] ;$

$T_{b}[\mathrm{~s} / \mathrm{km}]=\left(3600 / V_{\max }\right)+6624 \cdot\left[p-\left(3600 / 6624 \cdot V_{\max }\right)+0,0625\right] \cdot \alpha ;$

$L_{i}[\mathrm{~km}]$ is the generic i-arc length;

$V_{\max }=$ represents the presumed real speed $(90 \mathrm{Km} / \mathrm{h}$ for heavy veihcles);

$p[\%]$ represents the gradient;

$\delta=0 \rightarrow p \leq 0,025$;

$\delta=1 \rightarrow p>0,025$;

$\alpha=0 \rightarrow p \leq-\left(3600 / 6624 \cdot V_{\max }\right)+0,0625$;

$\alpha=1 \rightarrow p>-\left(3600 / 6624 \cdot V_{\max }\right)+0,0625$.

In the graphic network chart (figure 2), it is possible to see the results.

- The break time estimate is subject to two kinds of restraints: regulative and generic restraints. In the first case, the Cantarella and Festa [4] calculation system has been updated to the Legislative Order n.286 - 21/11/2005, that prescribes further restriction. In the second case two important time-wasters have been taken into account: the T2 transit Community paper that leads to one and a half hour time-waste during the Switzerland crossing, and the airport time-waste, which varies from 4 to 24 hours in accordance with airport nationality.

Relating to trucked air cargo operating costs estimate there are two cost levels: the first one concerns the transport service production and the second one the transport service purchase. Generally the transport service production costs are the costs that the road transport firms have to support to send a consignment from the $\mathrm{O}$ to the $\mathrm{D}$ place. On the contrary, transport service purchase costs are the costs that producers have to support to send a consignment from the $\mathrm{O}$ to the D place. Therefore they are called "prices" (Cantarella and Festa [4]). In this 
paper "costs" will be those concerning the trucked air cargo transport, and "prices" will be those concerning railway transports. A recent CSST research [6] has been adapted to the different features of this study that concerns lower payloads, different highway tolls and reduced fuel consumption. On the whole, the costs taken into consideration refer to: insurance, ownership, tyre use, truck purchase expenses, fuel, maintenance and repair, tolls and driver cost. If the running $\mathrm{km}$ cost of a five-axled articulated vehicle for a maximum of twenty six tons varies between $1,228 € / \mathrm{km}$ and $1,68 € / \mathrm{km}$, taking into account that the payload tons are on average 7,5 , the $\mathrm{km}$ cost of one ton will vary between 0,164 $€ / \mathrm{km}$ and $0,224 € / \mathrm{km}$ depending on the considered countries.

Relating to no-highway arcs the kilometric operating cost is similar to the highway cost: the main difference is the lack of tolls. So in this case the average $\mathrm{km}$ cost of one ton is $0,136 € / \mathrm{km}$.

\section{An intermodal freight system and its application to the industrial zones}

The current problem of intermodal freight is that only strong relationships are serviced. To change the current status it is necessary to activate an intermodal system able to lower the access threshold and specialize the carriers. This intermodal service should attract distributed traffic, optimize all transport arcs, integrate road, rail and sea freight, work as a network and be competitive with road transport. Metrocargo, an intermodal freight system, overcomes current problems by a horizontal loading system that reduces costs and time and a network of terminals giving freight transport the same flexibility as trucks (Nordio et al [7]). Its objectives are to move significant volumes of traffic from road to rail, to integrate sea, road, air and rail transport, to use each carrier for its best features with the aim of reducing environmental impacts and overall logistic costs and increasing efficiency. The system is based on a network of terminals connected by dedicated shuttle trains on fixed and scheduled itineraries. Load units are pre-arranged in the terminal, horizontally loaded on the first train and subsequently reload on other trains until they reach their final destination. In Italy a network of 20-25 terminals could cover $90 \%$ of the Italian territory connecting main ports, industrial areas and foreign railways. The terminals include: load arrival via truck, load delivery to trucking, stocking and preaddressing area, loading and unloading equipment.

With regard to pre-addressing equipment, the stocking area utilizes sections of motorized rollers, separately moved and synchronized. The loading machine loads and unloads cargo units. Cargo units are pre-addressed and temporarily stocked on roller ways, then directly loaded on trains using a proprietary loading machine. Special pallets are used to move the cargo units on rollers: 20' and 40'/45' containers and standard size swap bodies. The Logistic and Mobility Regional Plan [1] has found four "strategic points" as demand concentration poles and one point for goods exportation. They are the logistic centres of Prato, Guasticce and San Miniato, the future railway station of Tassignano-Capannori and the Pisa airport. In fact they are perfectly connected to roads and railways 
and they are also the barycentre of the industrial zones production. In these cases there is the concrete possibility of carrying out the Metrocargo transit point [7]. For this purpose see Figure 1 with a Metrocargo system double-ring scheme, with the different import-export points.

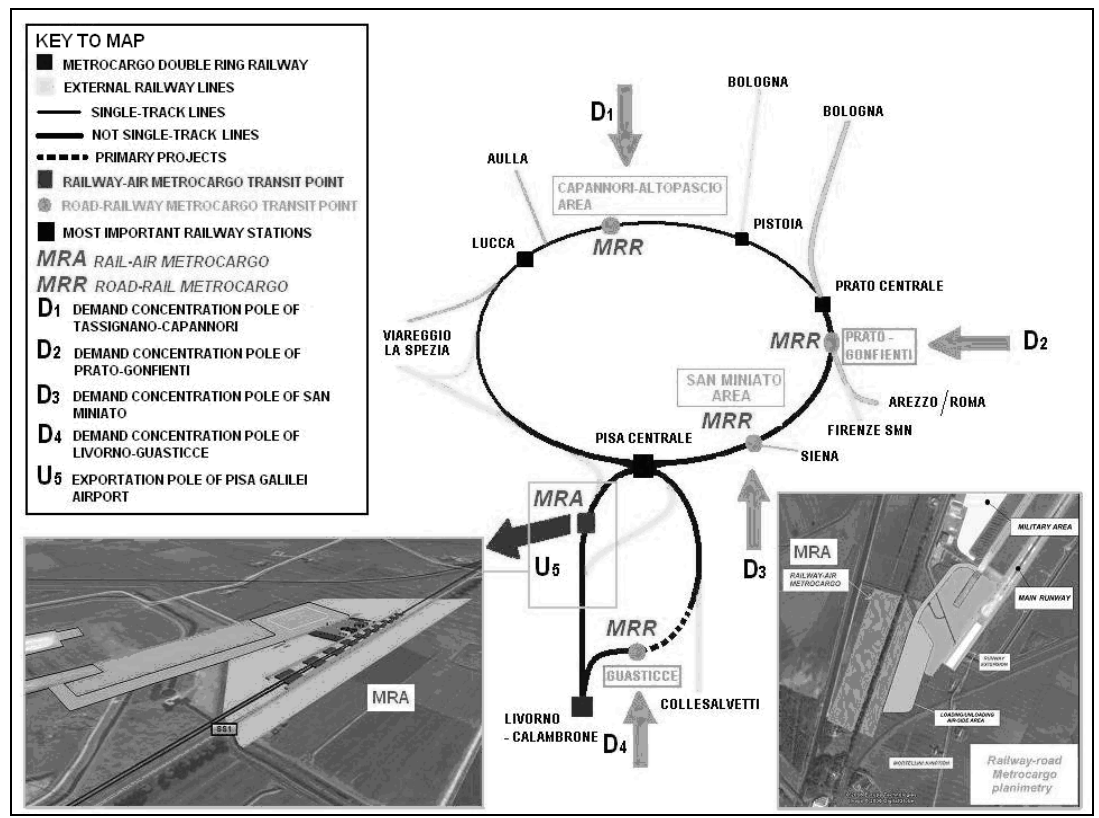

Figure 1: The double-ring scheme.

\section{Estimate of railway cargo travel time and operating costs}

The railway travel time is due to the sum of two components: the running and the break time. The first one is due to the assumption of a $50 \mathrm{~km} / \mathrm{h}$ running speed, and the second one makes due allowances for the Transit Points loading/unloading time (only 40') and possible wastes of time relating to the Pisa railway station crossing (graphic network chart in figure 2) (Nordio et al [7]).

The freight train $\mathrm{km}$-price varies from 12 to $13 €$. To compare the $\mathrm{km}$ operating cost of a trucked air cargo ton with the km-price of a freight train ton, it is necessary to determinate: the combined transport modulus of the railway's lines (the limit gauge PC22, which denotes a goods wagon of $3440 \mathrm{~mm}$ maximum height and $2500 \mathrm{~mm}$ maximum width, results in the most limiting condition of the railway network under examination); the linear modulus (freight train maximum length), which is about $400 \mathrm{~m}$; the maximum gradient $(1,4 \%)$; the maximum axial load; the air-pallets tipology; the occupation volumetric coefficient; and the ton $/ \mathrm{m}^{3}$ ratio concerning the tested goods type. To solve the last point in question, it has been necessary to interview the most important handler agents who transfer freight from their warehouses to the destination airports. The results are illustrated in table 1 . 
Table 1: $\quad$ Trucked air cargo quantification and regional airport export.

\begin{tabular}{|c|c|c|c|c|}
\hline & \multicolumn{3}{|c|}{ Weight-time ratio [t/y] } & \multirow{2}{*}{$\begin{array}{c}\text { Volumetric } \\
\text { flow } \\
{\left[\mathrm{m}^{3} / \mathbf{y}\right]}\end{array}$} \\
\hline & $\begin{array}{c}\text { Total } \\
\text { net } \\
\text { weight }\end{array}$ & $\begin{array}{c}\text { Tuscan } \\
\text { manufactured } \\
\text { net weight }\end{array}$ & $\begin{array}{c}\text { Tuscan } \\
\text { manufactured } \\
\text { gross weight }\end{array}$ & \\
\hline Trucked air cargo & 68.300 & 49.600 & 65.380 & $\approx 420.000$ \\
\hline Reg. airport export & 16.000 & 16.000 & 21.000 & $\approx 133.600$ \\
\hline Total & 84.300 & 65.600 & 86.380 & $\approx 554.000$ \\
\hline
\end{tabular}

Table 2: $\quad$ Pallets, wagons and freight train data.

\begin{tabular}{|c|c|}
\hline \multicolumn{2}{|c|}{ Pallet $\left(125 " \times 88 " \times 88 " \approx 15 \mathrm{~m}^{3}\right)$} \\
\hline $\begin{array}{l}\text { P. average net weight } 1 \\
\text { P. average gross } 2 \\
\text { weight }\end{array}$ & $\begin{array}{l}.785,5 \mathrm{~kg} \\
.340 \mathrm{~kg}\end{array}$ \\
\hline \multicolumn{2}{|c|}{ Wagon (H31 tipology) } \\
\hline $\begin{array}{l}\text { Loading floor length } \\
\text { Loading floor width } \\
2 \text { for side smooth } \\
\text { running doors measure } \\
\text { (hxl) bumpers } \\
\text { Length, } \\
\text { included } \\
\text { Limit load } \\
\text { Average tare } \\
\text { Capacity } \\
\text { Load volume } \\
\text { Load gross weight } \\
\text { Wagon gross weight } \\
\text { Occupation vol. } \\
\text { coefficient }\end{array}$ & $\begin{array}{l}19,760 \mathrm{~m} \\
2,6000 \mathrm{~m} \\
2,25 \times 9,67 \\
\mathrm{~m} \\
21,7 \mathrm{~m} \\
53 \mathrm{t} \\
29,0 \mathrm{t} \\
131,0 \mathrm{~m}^{3} \\
90 \mathrm{~m}^{3} \\
\approx 14 \mathrm{t} \\
43,000 \mathrm{t} \\
69 \%\end{array}$ \\
\hline
\end{tabular}

\begin{tabular}{|c|c|}
\hline \multicolumn{2}{|c|}{ Freight train } \\
\hline $\begin{array}{l}\text { Daily freight trains } \\
\#\end{array}$ & 2 \\
\hline Wagons \# & $12-13$ \\
\hline $\begin{array}{l}\text { Freight train load } \\
\text { volume }\end{array}$ & $\begin{array}{l}1.080- \\
1.170 \mathrm{~m}^{3}\end{array}$ \\
\hline $\begin{array}{l}\text { Gross weight of the } \\
\text { freight train load }\end{array}$ & $168-182 \mathrm{t}$ \\
\hline $\begin{array}{l}\text { Freight train tare } \\
\text { without engine }\end{array}$ & $348-377 \mathrm{t}$ \\
\hline $\begin{array}{l}\text { Freight train gross } \\
\text { weight without } \\
\text { engine }\end{array}$ & $516-559 t$ \\
\hline $\begin{array}{l}\text { Freight train length } \\
\text { without engine }\end{array}$ & $260-282 \mathrm{t}$ \\
\hline $\begin{array}{l}\text { Freight train length } \\
\text { with engine }\end{array}$ & $280-302 \mathrm{~m}$ \\
\hline $\begin{array}{l}\text { Double ring travel } \\
\text { time }\end{array}$ & $\approx 9 \mathrm{~h}$ \\
\hline Commercial speed & $<50 \mathrm{~km} / \mathrm{h}$ \\
\hline
\end{tabular}

Different air-pallet types have been considered and their compatibility and adaptability with different kinds of wagons has been tested. The data relating the best combination are illustrated in table 2 .

According to the above mentioned data, the final kilometric operating cost (price) amounts to $0,07 € / \mathrm{t} \cdot \mathrm{km}$. Should the freight train length reach its maximum (18 wagons), then the final kilometric operating cost (price) would be $0,04 € / \mathrm{t} \cdot \mathrm{km}$. 


\section{Distances, travel times and operating costs with the Metrocargo system}

After having described the computational methodology, the results regarding the operating costs referring to the highway rather than highway arcs and railway arcs are summarized in table 3 .

Considering table 3 and the other results explained in the previous paragraphs, it is possible to build the graphic network chart of distances, travel times and operating costs (figure 2) calculated for each arc.

Table 3: $\quad$ Kilometric operating costs compendium $[€ / \mathrm{t} \cdot \mathrm{km}]$.

\begin{tabular}{|c|c|c|}
\hline Highway arcs & Not -highway arcs & Railway arcs \\
\hline $0,164-0,224 € / \mathrm{t} \cdot \mathrm{km}$ & $0,136 € / \mathrm{t} \cdot \mathrm{km}$ & $0,07 € / \mathrm{t} \cdot \mathrm{km}$ \\
\hline
\end{tabular}

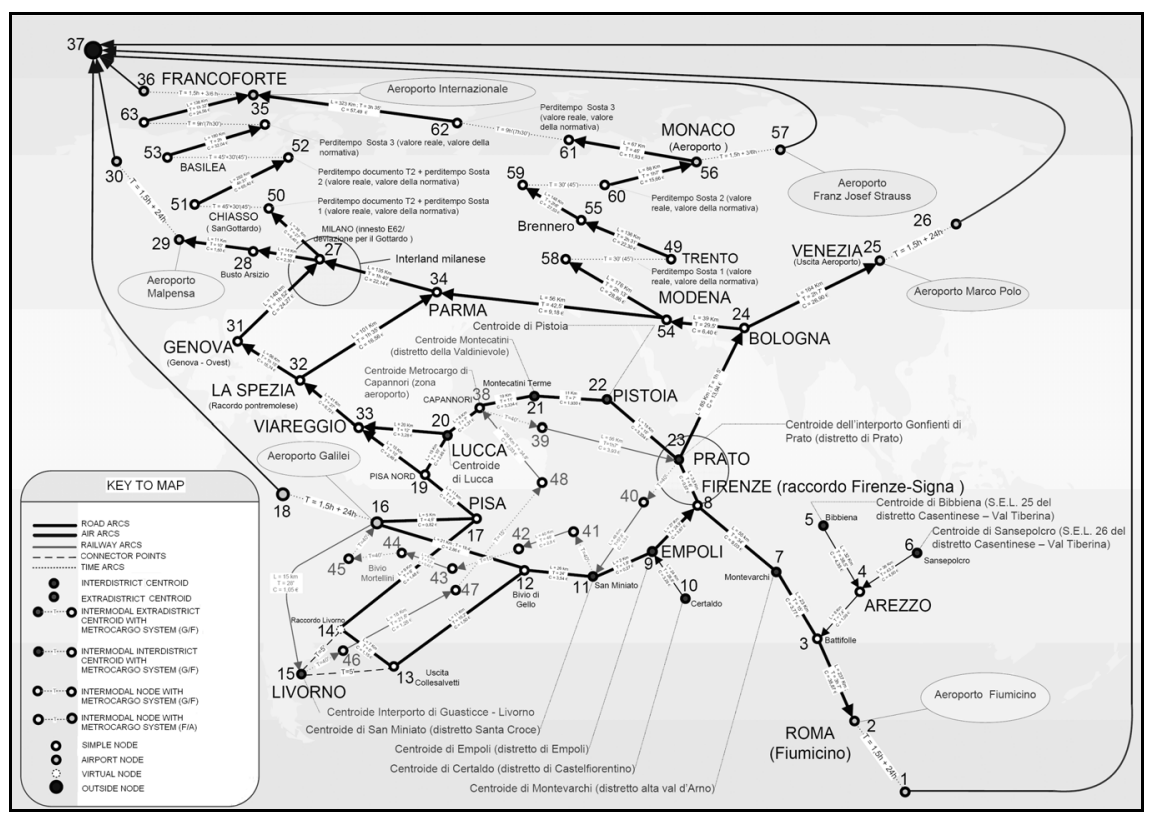

Figure 2: Graphic network chart of distances, travel times and operating costs.

\section{Estimate of trucked air cargo and railway cargo total costs}

The research proceeds to quantifying the time monetary value both in the event of trucked air cargo and in the event of rail transport, so as to define the total cost. For this purpose a trade-off coefficient has been calculated for both cases. The trade-off coefficient is a multiplier that allows one to find the time monetary value. 
In order to estimate the trucked air cargo trade-off coefficient, it has been necessary to interview both the most important handler agents and some of the small trucked air cargo carriers who transfer freight from regional warehouses to the destination airports. At the beginning, the same question has been asked to the above mentioned workers types: "How much money would you pay for the gain of one hour of time?". All interviewed workers have declared values lower than the actual kilometric cost of a trucked air cargo ton carriage, which amounts to $8-9 € / \mathrm{t} \cdot \mathrm{km}$. This could induce the idea that the time monetary value is not very important. But if a handler agent could halve the travel time of a wide ranging truck-air cargo transport, he should be ready to pay much more than $8-9 € / \mathrm{t} \cdot \mathrm{km}$. In fact he could reach the destination airport having enough time to catch the previous air connection. So time value depends on the truck-air cargo transport range and the width of the chronological window included between the first working take-off and the following. For this reason the time monetary value has been increased because of the presence of many wide ranging trucked air cargo transports that in addition reach hubs that can assure short take-off chronological windows. This problem does not have important consequences when the truck air cargo transport concerns the small handler agents that transfer freight from regional warehouses to the Italian destination airports. All things considered, the trade-off coefficient value is worth approximately $\alpha_{\text {t.a.c }}=7,2 €$.

In order to estimate the trade-off coefficient for rail transportation, it is necessary to deepen some aspects about the reliability and punctuality weight.

A very important aspect has to be pointed out: the handler does not need to save time for itself, but he needs to save the time oriented to maximize the probabilities of respecting the time windows imposed by the combined transport type taken into consideration. To put it clearer, if it takes one hour less in reaching an established airport, during one year the probability of overrunning the limits of the imposed time windows will decrease. But there is a limit to all this, because time saving will never be as profitable a choice as the reliability guarantee is. The Metrocargo system results in a much more reliable and regular system than road haulage and ordinary rail transport. The consequence of this demonstration leads us to the following question: "Would it be possible to weigh reliability and regularity as a time function aiming to correct the trade-off coefficient in the rail case vis-à-vis the value given in road haulage?" A possible answer could be the following one. Supposing a time window of 8 hours within which our handler has to deliver the cargo to the D airport. Its representation on a cartesian plane will have: on the abscissa axis, " $\mathrm{T}$ " time; on the ordinate axis, the supposed " $\mathrm{C}$ " cost of $\mathrm{T}$ time. The supposed time cost will vary in function of the time itself, because the handler will be oriented to give a poor monetary value to the first hours of the time window and an even greater value to the supposed $\mathrm{C}$ cost of the last hours of the time window. However there is a $\mathrm{C}_{\max }$, because, in case the consignment should overrun the time window, it would be obliged to wait for the next loading shipment, and such time has a cost. Consequently a function $\mathrm{F}_{\mathrm{RR}}$ - reliability and regularity - can be put on the ordinate axis, and it will reach its maximum in $\mathrm{T}=0$, as in the case of full reliability and punctuality the time cost is insignificant, considering that nobody 
would pay just to save a travel hour knowing he will arrive in time. On the other hand in the case of always less reliable and regular systems the supposed time cost considerably increases its value. Then, when the supposed time cost increases, the function $F_{R R}$ decreases until it dissolves when $C_{\max }$ is reached. Actually when somebody is ready to pay so much to save time, it means that the transportation system is completely unreliable.

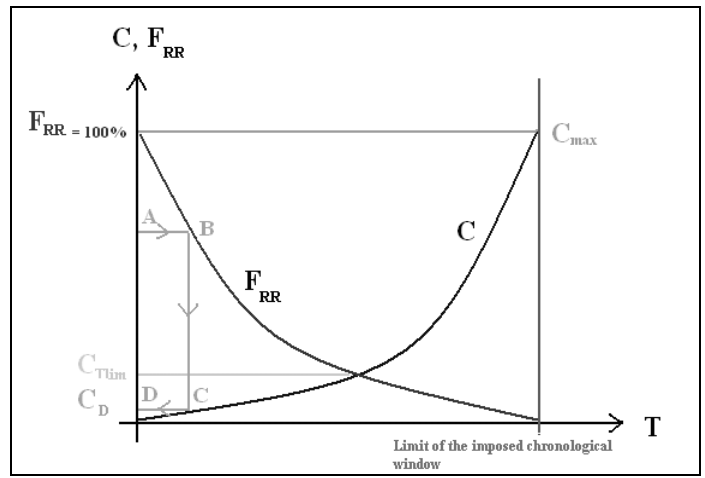

Figure 3: Cost and time diagram.

On the basis of the interviews, the cost that the handlers would be willing to pay for saving an hour of time, in which position of this diagram would this result be? It would not certain be next to zero, nor to the maximum or near to it, because the interviewed handler thinks of an average cost. Then it could be directly placed by the central time window. Moreover, it would meanwhile represent a limit: the interviewed people have almost always stated that they would not pay for an hour of saved time, because time is never so important as reliability and regularity are. Consequently this limit can be placed at the intersection line of the two diagrams. A certain value of the $F_{R R}$ would correspond to this supposed time limit cost. Given the curves (here supposed, as only the quality trend is known) given the $\mathrm{C}_{\max }$ (according to the handlers interviewed), given the $C_{T_{\text {lim }}}$, once fixed at given reliability and regularity for a system alternative to that under examination, the course A-B-C-D can be outlined to see how much the weight of the time cost can be reduced for this alternative system, as shown in figure 3 .

In our case $C_{T_{\text {lim }}}=7,2 €$ and this is the trade-off for the road network; but the trade-off of the railway network has to be assumed equal to a $C_{D}$, because this alternative system has a superior reliability and regularity. Let us approximately assume a trade-off ratio between the two coefficients of $4: 1$, that is the $C_{D}$ value $=1 / 4 \cdot 7,2=1,8 €$; this value agrees with the statements of the interviewed handlers on the matters of reliability and safety, which are considered more important than the time factor. This way of dealing is valid if the following condition is observed: the distance time foreseen for the railway section has to obviously be inferior to that of the fixed time window. All things considered, the trade-off coefficient value is worth approximately $\alpha_{\text {r.c. }}=1,8 €$. 
In conclusion, the total costs are given by the following formula:

$$
C_{i j}=c_{i j}+\alpha T_{i j}
$$

where " $\mathrm{i}$ " is the initial node of the $\mathrm{ij}$ arc, " $\mathrm{j}$ " is the final node of the $\mathrm{ij}$ arc, " $\mathrm{c}_{\mathrm{ij}}$ " is the operating cost of the $i j$ arc, " $\mathrm{C}_{\mathrm{ij}}$ " is the total cost of the $\mathrm{ij}$ arc, " $\mathrm{T}_{\mathrm{ij}}$ " is the travel time of the ij arc, and " $\alpha$ " is the trade-off coefficient.

Therefore it is possible to built a graphic network chart that shows for each arc, as the previous one in figure 2 , the total cost. To give a better explanation, see table 4 as an example (the grey column shows Metrocargo).

Table 4: Total costs of the itineraries that link Prato to all the D-centroids.

\begin{tabular}{|l|l|l|l|l|l|l|l|}
\hline $\boldsymbol{D}$ & Pisa & Pisa & Monaco & Venezia & Fiumicino & Malpensa & Frankfurt \\
\hline T.Cost & $199 €$ & $203 €$ & $237 €$ & $247 €$ & $267 €$ & $270 €$ & $403 €$ \\
\hline
\end{tabular}

It is possible to observe that the "total cost-distance" between Prato and Monaco airport is lower than the "total cost-distance" between Prato and Venezia airport or Prato and Roma-Fiumicino airport, although these airports are closer than the Monaco airport to Prato. Moreover, the Metrocargo system allows one to reduce the costs.

\section{References}

[1] Tuscany Region, Regional Mobility and Logistics Plan of Tuscany Region, Tuscany Region edition: Florence, 2003.

[2] Dalla Chiara, B., Marigo, D., Benzo, G., Interports e Intermodal terminals, Ulrico Hoepli: Milano, 2002.

[3] Cascetta, E., Theory and Methods for Transport System Engineering, UTET: Torino, 1998.

[4] Cantarella, G.E., Festa, D.C., Models and Methodologies for Traffic Engineering, Franco Angeli: Milano, 1998.

[5] CNR bulletin, Instructions to define the road investment profitability relating to $\mathrm{I}^{\circ}$ e $\mathrm{II}^{\circ}$ kind roads, Italy, A.XVII, n. 91, 2 May 1983.

[6] CSST research - 2005, www.csstspa.it.

[7] Nordio, A., Porta, G., Vignolo, M.G., The modal riequilibrium through the exploitation of the railway and maritime transport of goods with the use of innovative intermodal technologies. Limits and perspectives of development of the railway transport of the goods, Franco Angeli: Milano, 2006. 